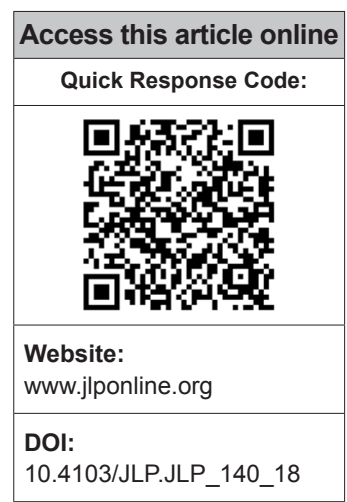

Department of Microbiology, Sanjay Gandhi Post Graduate Institute of Medical Sciences, ${ }^{1}$ Department of Microbiology, RML Institute of Medical Sciences, Lucknow, Uttar Pradesh, India

Address for correspondence:

Dr. Atul Garg,

Department of

Microbiology,

Sanjay Gandhi Post

Graduate Institute of

Medical Sciences,

Lucknow - 226014 ,

Uttar Pradesh, India.

E-mail: atulgargsgpgi@ gmail.com

Submission: 26-12-2018 Accepted: 06-01-2019

\title{
Can rapid dengue diagnostic kits be trusted? A comparative study of commercially available rapid kits for serodiagnosis of dengue fever
}

\author{
Atul Garg, Jaya Garg'1, Dharam Veer Singh, TN Dhole
}

\section{Abstract:}

BACKGROUND: Dengue virus infection is an important emerging disease of the tropical and subtropical regions and is mainly diagnosed by serological detection of NS1 antigen and IgM antidengue antibodies. Since enzyme-linked immunosorbent assay (ELISA) facilities are not easily available at most diagnostic centers, so most of them use various commercially available rapid diagnostic tests (RDTs) kits.

AIMS AND OBJECTIVES: This study was designed to access the diagnostic accuracy of four commercially available and widely used RDTs for serodiagnosis of dengue virus infection in Indian laboratories.

SUBJECTS AND METHODS: The study was conducted at Department of Microbiology, G.S.V.M Medical College, Kanpur, India, to estimate the sensitivity and specificity of following RDTs: (1) Dengue Cassette (Panbio, Australia), (2) Bioline Dengue Duo (SD Diagnostics, Korea), (3) Dengue Day 1 test (J Mitra and Co., India), and (4) Dengucheck Duo (Tulip Diagnostics, India) on 72 confirmed dengue serum samples that were positive by dengue reverse transcription-polymerase chain reaction, dengue NS1, and IgM ELISA along with 80 serum samples from nondengue febrile illness patients.

RESULTS: The majority of the RDTs demonstrated low sensitivity but good specificity for detecting NS1 antigen. Detection of antidengue IgM antibodies by RDTs demonstrated low sensitivity ranging from $27.8 \%$ to $77.7 \%$. However, specificity was generally higher $(50 \%-86.2 \%)$ and more consistent across the assays.

CONCLUSION: The study results differed markedly from the RDTs manufacturers' claimed performance characteristics. Therefore, the RDT results should be interpreted cautiously and ELISA should be performed as far as possible for serodiagnosis of dengue virus infection.

Key words:

Dengue, enzyme-linked immunosorbent assay, IgM antibodies, NS1 antigen, rapid diagnostic test kits

\section{Introduction}

$\mathrm{D}$ engue virus is an important vector-borne disease and is found largely in areas of tropics and subtropics. The disease is now endemic in $>100$ countries in Africa, South America, Eastern Mediterranean, Southeast Asia, and the Western Pacific,

This is an open access journal, and articles are distributed under the terms of the Creative Commons Attribution-NonCommercial-ShareAlike 4.0 License, which allows others to remix, tweak, and build upon the work non-commercially, as long as appropriate credit is given and the new creations are licensed under the identical terms.

For reprints contact: reprints@medknow.com threatening $>2.5$ billion people. ${ }^{[1]}$ Dengue is believed to infect $50-100$ million people worldwide a year with half a million life-threatening infections requiring hospitalization, resulting in approximately 12,500-25,000 deaths. ${ }^{[2]}$ In terms of morbidity, mortality, and economic costs, dengue virus infection is the most important mosquito-borne virus disease in the world, and the incidence and spread of the disease

How to cite this article: Garg A, Garg J, Singh DV, Dhole TN. Can rapid dengue diagnostic kits be trusted? A comparative study of commercially available rapid kits for serodiagnosis of dengue fever. $J$ Lab Physicians 2019;11:63-7. 
are increasing. There have been several epidemics reported from India; from Calcutta (1963), Visakhapatnam (1964), Vellore (1968), Ajmer (1969), Kanpur (1969), Jalore of Rajasthan (1985), Chandigarh (2002), Mumbai (2004), Ludhiana (2007), Delhi (1996, 2003. 2006, AND 2010), and more recently Kanpur. ${ }^{[3-11]}$

The dengue virus HAS four distinct but antigenically related serotypes and infection produces a spectrum of clinical illness, ranging from an asymptomatic or mild febrile illness to classic dengue fever to the most severe form of illness, dengue hemorrhagic fever (DHF) and dengue shock syndrome (DSS). Population-based studies suggest that asymptomatic infections are the main outcome of dengue virus exposure. However, whenever DHF occurs, it is associated with high morbidity and mortality. ${ }^{[12-14]}$

Dengue fever can be diagnosed by isolation of the virus, serology or reverse transcription-polymerase chain reaction (RT-PCR). Diagnostic laboratories in most developing countries lack the facilities for the diagnosis of dengue by any means other than serology. Among serological techniques, detection of NS1 antigen and antidengue IgM antibody is commonly used and several assays in various formats are available ranging from capture enzyme-linked immunosorbent assay (ELISA) to rapid diagnostic tests (RDTs) using immune chromatographic or immunoblot technologies. The timely diagnosis of dengue allows earlier implementation of supportive therapy and monitoring, thus reducing the risk of complications such as DHF or DSS, especially in countries where dengue is endemic. ${ }^{[13]}$

Several western studies have compared dengue RDTs with reference assays; ${ }^{[14]}$ however, till date, diagnostic accuracy of these tests has not been reliably established with acute-phase specimens in the Indian subcontinent. The present article documents a diagnostic accuracy assessment of four commercially available RDTs tested against a precharacterized panel of specimens.

\section{Subjects and Methods}

This prospective study was conducted from September 2016 to August 2017 in collaboration of Virology Laboratory, Department of Microbiology, SGPGIMS, Lucknow, and G.S.V.M Medical College, Kanpur, India. These laboratories are regional referral laboratory for vector-borne diseases and have facilities for ELISA and PCR. The study was cleared by institute ethics committee, and written informed consent was collected from enrolled patients.

During the study period, more than 3000 acute-phase serum samples from clinically suspected dengue patients were collected at L.L.R Hospital, GSVM Medical College, Kanpur. All samples were tested for dengue by RT-PCR, antidengue IgM antibodies, and NS1 antigen detection by ELISA. The kits for antidengue IgM ELISA were provided by National Institute of Virology, Pune, India, and NS1 ELISA kits were procured from Panbio, Queensland, Australia. A panel of 152 serum samples was selected for conducting this study; it consisted of 72 dengue RT-PCR-positive samples that were also positive for both antidengue IgM and NS1 antigen and 80 serum samples negative for dengue by RT-PCR, IgM, and NS1 ELISA. Of these 80 dengue-negative samples, 40 were collected from healthy individuals, 20 from malaria patients, 10 from Japanese encephalitis (JE) patients, and 10 from enteric fever patients. All sera were stored at $-20^{\circ} \mathrm{C}$ until thawed for testing.

Before conducting the study, a survey was done about the use of commercially available rapid diagnostic kits by various private and government laboratories which do not have ELISA facilities for diagnosis of dengue fever, and based on survey results, following kits were selected: (1) Dengue Duo cassette (Panbio, Australia), (2) Bioline Dengue Duo (SD diagnostics, Korea), (3) Dengue day 1 test (J Mitra and Co., India), and (4) Dengucheck Combo (Tulip Diagnostics, India). Among the selected kits, Dengue Duo Cassette detected only antidengue $\operatorname{IgM}$ and IgG, whereas rest three kits detected NS1, IgM, and IgG. Kit details and manufactures claims of kits sensitivity and specificity are tabulated in Table 1. All specimens were randomized and relabeled with study codes to ensure that the staff performing the RDTs was blinded to sample identity and assays were performed in accordance with the manufacturers' instructions contained within the RDT kits. Diagnostic accuracy of the tested RDT was determined in relation to precharacterized results for each test sample. Tabulation, management, and analysis of raw data were carried out using Microsoft Excel (Microsoft, Inc., United States). A $2 \times 2$ table was constructed in which the predetermined results of test serum was cross-tabulated with the tested RDT (the assay under investigation) to define true-positive, false-positive, false-negative, and true-negative values. Standard diagnostic accuracy indices of the tested RDTs such as sensitivity, specificity, negative predictive value, and positive predictive value were calculated with their $95 \%$ confidence intervals (95\% CI) using SPSS for Windows (Version 14; SPSS, Inc., Chicago, IL, USA).

\section{Results}

A total of 152 patients with median age 35.5 years (range 20-68) and male: female ratio of 1.45:1 were enrolled in the study. The median time from fever onset to presentation was 6 days (range 4-9 days). Seventy-two 
Table 1: Details of rapid diagnostic test kits used in study

\begin{tabular}{|c|c|c|c|c|c|c|c|c|c|c|}
\hline \multirow[t]{2}{*}{ Product name } & \multirow[t]{2}{*}{ Manufacturer } & \multirow[t]{2}{*}{ Sample type } & \multirow{2}{*}{$\begin{array}{c}\text { Sample } \\
\text { volume } \\
\text { (ul) }\end{array}$} & \multirow{2}{*}{$\begin{array}{c}\text { Storage } \\
\text { conditions } \\
\left({ }^{\circ} \mathrm{C}\right)\end{array}$} & \multirow{2}{*}{ Format } & \multirow{2}{*}{$\begin{array}{l}\text { Maximum } \\
\text { time to } \\
\text { negative }\end{array}$} & \multicolumn{2}{|c|}{$\begin{array}{l}\text { Manufacturer claim } \\
\text { NS1 antigen (\%) }\end{array}$} & \multicolumn{2}{|c|}{$\begin{array}{l}\text { Manufacturer claim IgM } \\
\text { antibody detection (\%) }\end{array}$} \\
\hline & & & & & & & Sensitivity & Specificity & Sensitivity & Specificity \\
\hline $\begin{array}{l}\text { Dengue Duo } \\
\text { Cassette }\end{array}$ & $\begin{array}{l}\text { Pan Bio, } \\
\text { Australia }\end{array}$ & $\begin{array}{l}\text { Whole blood/ } \\
\text { serum/plasma }\end{array}$ & 10 & $2-30$ & $\begin{array}{l}\text { Lateral } \\
\text { flow }\end{array}$ & $15-20 \mathrm{~min}$ & - & - & 98 & 98 \\
\hline $\begin{array}{l}\text { Bioline Dengue } \\
\text { Duo }\end{array}$ & $\begin{array}{l}\text { Standard } \\
\text { Diagnostic, } \\
\text { Korea }\end{array}$ & $\begin{array}{l}\text { Whole blood/ } \\
\text { serum/plasma }\end{array}$ & 10 & $1-30$ & $\begin{array}{l}\text { Lateral } \\
\text { flow }\end{array}$ & $15-20 \mathrm{~min}$ & 92 & 98 & 94 & 96 \\
\hline $\begin{array}{l}\text { Dengue Day } \\
1 \text { test }\end{array}$ & $\begin{array}{l}\text { J. Mitra and } \\
\text { Co., India }\end{array}$ & Serum/plasma & 70 & $2-30$ & $\begin{array}{l}\text { Lateral } \\
\text { flow }\end{array}$ & $20 \mathrm{~min}$ & 96 & 98 & 95 & 97 \\
\hline $\begin{array}{l}\text { Dengucheck } \\
\text { Combo }\end{array}$ & $\begin{array}{l}\text { Zypher (Tulip). } \\
\text { India }\end{array}$ & Serum/plasma & 75 & $4-30$ & $\begin{array}{l}\text { Lateral } \\
\text { flow }\end{array}$ & $15-20$ & 100 & 100 & 93 & 95 \\
\hline
\end{tabular}

patients were RT-PCR positive and also positive to both to NS1 antigen and antidengue IgM by ELISA, while 80 dengue-negative serum samples were included as control. None of the dengue-negative serum samples were positive for dengue NS1/IgM by ELISA; however, five JE samples were positive for dengue IgM by RDTs.

The majority of the RDTs demonstrated good sensitivity and specificity for detecting NS1 antigen. Bioline Dengue Duo and Dengucheck Combo showed 100\% sensitivity and specificity while Dengue day 1 test demonstrated sensitivity of $94.4 \%$ (95\% CI, 86.3-98.4) and specificity of $100 \%$ (95\% CI, $98.5 \%-100 \%$ ). Detection of antidengue IgM antibodies by RDTs demonstrated low sensitivity ranging from $27.8 \%$ (95\% CI, 17.8\%-39.6\%; Dengue Day 1 test) to $77.7 \%$ (95\% CI, $66.4 \%-86.7 \%$; Dengucheck Combo). However, specificity was generally higher and more consistent across the assays 50\% (95\% CI, 38.6\%-61.40\%; Dengucheck Combo) to $100 \%$ (95\% CI, $97.8 \%-100.0 \%$; Bioline Dengue Duo). Bioline Dengue Duo has 100\% positive predictive value both for NS1 antigen and IgM antibodies and maximum false-positive results were found with Dengue check combo followed by Dengue Day 1 test. The overall diagnostic accuracy of all assays is presented in Table 2.

\section{Discussion}

Dengue virus is single-stranded RNA virus that belongs to the family Flaviviridae and the genus Flavivirus. The Flaviviridae family also includes other medically important vector-borne viruses such as West Nile virus, Yellow fever virus, JE virus, and St. Louis encephalitis virus. Dengue viruses are arboviruses transmitted primarily to humans through the bite of an infected female Aedes species mosquito. Transmission may also occur through transfusion of infected blood or as occupational exposure in healthcare settings (e.g., needle stick injuries); cases of vertical transmission have also been described in the literature. ${ }^{[15]}$ Early clinical recognition and laboratory confirmation of dengue infection and anticipatory treatment for those who develop DHF or DSS can save lives. No antiviral agent exists for dengue infection treatment, the key to the successful management lies in early laboratory diagnosis with timely and judicious supportive care and close monitoring of vital signs and hemodynamic status, fluid balance, and hematologic parameters. ${ }^{[16]}$

In the past 50 years, the incidence of dengue has increased 30-fold worldwide, largely as a consequence of population migration, rise in growth of unplanned cities, increased travel, water pooling in cities, poor vector control measures, etc. ${ }^{[10]}$ Between 2006 and 2012, the National Vector Borne Diseases Control Program, Government of India, reported an annual average of 20,474 dengue cases and 132 death associated with dengue. However, during the same time period, according to a recent study by US and Indian researchers, six million annual clinically diagnosed dengue cases were present; almost 300 times greater than the number of cases that had been officially reported. ${ }^{[17]}$ The major reason for low official reporting is due to Indian governments selective dengue surveillance system as it includes data only of ELISA confirmed cases from 347 Sentinel Surveillance Virology Laboratories and 14 Apex Referral Laboratories, thus capturing only $0.35 \%$ of the annual number of clinically diagnosed dengue cases in India. ${ }^{[18]}$ Other minor reasons responsible for low official reporting are inadequate infrastructure for dengue diagnosis augmented with busy doctors not finding the time to fill in paperwork to the difficulty of accurate diagnosis. Further, many people are treated in private hospitals, which rarely report cases of dengue to the authorities.

In Indian subcontinent, serological tests using rapid kits are most commonly used to diagnose dengue fever. Since ELISA facilities are not easily available at most diagnostic centers, there are several rapid diagnostic kits available and their market continues to grow, largely without regulation by national and international testing authorities. There is a concerning lack of independent verification of the diagnostic accuracy claimed by manufacturers, which could lead to widespread misdiagnosis of dengue infection. 
Table 2: Overall diagnostic accuracy of rapid diagnostic test kits used in the study

\begin{tabular}{|c|c|c|c|c|c|c|c|}
\hline \multirow[t]{2}{*}{ Character } & \multirow{2}{*}{$\begin{array}{c}\text { Dengue Duo } \\
\text { Cassette } \\
\text { IgM }\end{array}$} & \multicolumn{2}{|c|}{ Bioline Dengue Duo } & \multicolumn{2}{|c|}{ Dengucheck Combo } & \multicolumn{2}{|c|}{ Dengue Day 1 test } \\
\hline & & NS1 & $\lg M$ & NS1 & $\lg M$ & NS1 & $\lg M$ \\
\hline $\begin{array}{l}\text { Sensitivity } \\
(95 \% \mathrm{Cl})\end{array}$ & $61.1 \%(48.8-72.3)$ & $100 \%(94.6-100)$ & $44.5 \%(32.7-56.6)$ & $100 \%(94.6-100)$ & $77.7 \%(66.4-86.7)$ & $94.4 \%(86.3-98.4)$ & $27.8 \%(17.8-39.6)$ \\
\hline $\begin{array}{l}\text { Specificity } \\
(95 \% \mathrm{Cl})\end{array}$ & $95.1 \%(87.7-98.6)$ & $100 \%(95.5-100)$ & $100 \%(97.5-100)$ & $100 \%(95.5-100)$ & $50 \%(38.6-61.4)$ & $100 \%(98.5-100)$ & $65 \%(53.5-75.3)$ \\
\hline $\begin{array}{l}\text { Positive } \\
\text { predictive } \\
\text { value }(95 \% \mathrm{Cl})\end{array}$ & $91.7 \%(80-97.6)$ & $100 \%(94.6-100)$ & $100 \%$ & $100 \%(94.6-100)$ & $58.3 \%(47.8-68.3)$ & $100 \%$ & $41.6 \%(27.6-56.8)$ \\
\hline $\begin{array}{l}\text { Negative } \\
\text { predictive } \\
\text { value }(95 \% \mathrm{Cl})\end{array}$ & $73.1 \%(63.4-81.3)$ & $100 \%(95.5-100)$ & $66.7 \%(57.4-75.1)$ & $100 \%(95.5-100)$ & $71.4 \%(57.8-82.7)$ & $95.2 \%(88.2-98.6)$ & $50 \%(40-60)$ \\
\hline $\begin{array}{l}\text { Positive } \\
\text { likelihood ratio }\end{array}$ & $12.2(4.6-32.3)$ & - & - & - & $1.56(1.21-2.00)$ & - & $0.79(.49-1.28)$ \\
\hline $\begin{array}{l}\text { Negative } \\
\text { likelihood ratio }\end{array}$ & $0.41 \%(0.31-0.55)$ & - & $0.56 \%(0.45-0.68)$ & - & $0.44 \%(0.27-0.72)$ & $0.06(0.02-0.14)$ & $1.11(0.90-1.38)$ \\
\hline
\end{tabular}

Table 3: Comparative table of sensitivity and specificity of various rapid diagnostic test kits in different studies

\begin{tabular}{|c|c|c|c|c|c|}
\hline Kit used & Serological target & Sensitivity & Specificity & Place of study & Reference number \\
\hline \multirow[t]{11}{*}{ Bioline Dengue Duo } & NS1 & 70 & 73 & Bangkok & {$[23]$} \\
\hline & $\lg M$ & 75 & 97 & & \\
\hline & NS1 & 58 & - & Mexico & [12] \\
\hline & $\lg M$ & 96 & 98 & & \\
\hline & NS1 & 76 & 98 & Malaysia & [24] \\
\hline & NS1 & 81 & 98 & Singapore & [22] \\
\hline & $\lg M$ & 90 & 90 & Mexico & [25] \\
\hline & $\lg M$ & 10 & 99 & Vietnam & [21] \\
\hline & $\lg M$ & 69 & 86 & India & [26] \\
\hline & IgM & 70 & 76 & Nepal & [20] \\
\hline & IgM & 17 & 98 & India & [19] \\
\hline \multirow[t]{6}{*}{ Dengue Duo Cassette } & $\lg M$ & 65 & 97 & India & [19] \\
\hline & $\lg M$ & 100 & 88 & Thailand & [27] \\
\hline & $\lg M$ & 84 & 100 & Barbados & [19] \\
\hline & $\lg M$ & 100 & 92 & Netherland & [28] \\
\hline & $\lg M$ & 76 & 75 & Columbia & [29] \\
\hline & IgM & 67 & 91 & Vietnam & [21] \\
\hline Dengucheck Combo & $\lg M$ & 3 & 99 & India & [19] \\
\hline Dengue Day 1 test & NS1 only evaluated & 99 & 96 & India & [30] \\
\hline
\end{tabular}

The majority of the RDTs tested in this study demonstrated low sensitivity for IgM detection; ranging from $27.8 \%$ (Dengue Day 1 test) to $77.7 \%$ (Dengucheck Combo); the specificity was generally higher and more consistent across the assays and ranged from 50\% (Dengucheck Combo) to 100\% (Bioline Dengue Duo). In a similar study, Blacksell et al. compared the diagnostic accuracy of eight commercial RDTs for the diagnosis of acute dengue virus infection and reported low sensitivity ranging from $6 \%$ to $65 \%$ and specificities ranged from $69 \%$ to $100 \% \cdot{ }^{[14]}$ They concluded that most of the RDT kits did not meet the performance claim of manufacturers and their results should be interpreted cautiously.

There are few studies from the Indian subcontinent on estimation of dengue IgM antibodies by single rapid kit using ELISA as gold standard diagnostic test. Moorthy et al. from CMC Vellore evaluated Panbio Dengue Duo Cassette for antidengue IgM antibody detection and reported a sensitivity and specificity of $81 \%$ and $75 \%$, respectively. ${ }^{[19]}$ Similarly, Pun et al. from Nepal evaluated Bioline Dengue Duo and reported a sensitivity and specificity of $70 \%$ and $76 \%$, respectively; they further concluded that overall performance of the rapid test is poor and other options should be explored for early diagnosis of dengue virus infection. ${ }^{[20]}$ Bioline Dengue Duo kit for antidengue IgM antibody has been evaluated extensively by many workers with conflicting results. Mai et al. ${ }^{[21]}$ from Vietnam reported a sensitivity of $10 \%$ and specificity $99 \%$; whereas high sensitivity and specificity of $94 \%$ and $92 \%$ have been reported by Gan et al. from Singapore. ${ }^{[22]}$ There is no study from India till date to evaluate the diagnostic accuracy of all commonly available 
commercially available RDTs. Few Indian and foreign studies with similar background are tabulated in Table 3 .

The study results differed markedly from the RDT manufacturers' claimed performance characteristics; we conclude that NS1 antigen detection by RDTs is reliable for diagnosis of early acute dengue fever; however, RDTs are unreliable to detect IgM antibodies for diagnosing late acute dengue fever. Accordingly, it is need of the hour to work to develop better RDTs with strict quality control and ELISA should be performed as far as possible for serodiagnosis of acute dengue virus infection.

\section{Acknowledgment}

We gratefully acknowledge the funding received from Indian Council of Medical Research, New Delhi (VIR/24/2011/ECD-1).

\section{Financial support and sponsorship}

We gratefully acknowledge the funding received from Indian Council of Medical Research, New Delhi (VIR/24/2011/ECD-1).

\section{Conflicts of interest}

There are no conflicts of interest.

\section{References}

1. Bhatt S, Gething PW, Brady OJ, Messina JP, Farlow AW, Moyes CL, et al. The global distribution and burden of dengue. Nature 2013;496:504-7.

2. Gubler DJ. Epidemic dengue/dengue hemorrhagic fever as a public health, social and economic problem in the $21^{\text {st }}$ century. Trends Microbiol 2002;10:100-3.

3. Pavri KM, Banerjee G, Anderson CR, Aikat BK. Virological and serological studies of cases of haemorrhagic fever in Calcutta: material collected by the Institute of Post-Graduate Medical Education and Research, Calcutta. Indian J Med Res 1964;52:692-7.

4. Cherian T, Ponnuraj E, Kuruvilla T, Kirubakaran C, John TJ, Raghupathy $\mathrm{P}$, et al. An epidemic of dengue haemorrhagic fever \& dengue shock syndrome in \& around Vellore. Indian J Med Res 1994;100:51-6.

5. Chaturvedi UC, Mathur A, Kapoor AK, Tandon HO, Mehrotra RM. Clinico-virological study of the recurrence of dengue epidemic with haemorrhagic manifestations at Kanpur during 1969. Indian J Med Res 1972;60:329-33.

6. Kabilan L, Balasubramanian S, Keshava SM, Thenmozhi V, Sekar G, Tewari SC et al. Dengue disease spectrum among infants in the 2001 dengue epidemic in Chennai, Tamil Nadu. India. J Clin Microbiol 2003;41:3919-21.

7. Padbidri VS, Dandawate CN, Goverdhan MK, Bhat UK, Rodrigues FM, D'Lima LV, et al. An investigation of the aetiology of the 1971 outbreak of febrile illness in Jaipur city, India. Indian J Med Res 1973;61:1737-43.

8. Balaya S, Paul SD, D'Lima LV, Pavri KM. Investigation on an outbreak of dengue in Delhi in 1967. Indian J Med Res 1969;57:767-74.

9. Dar L, Broor S, Sengupta S, Xess I, Seth P. The first major outbreak of dengue hemorrhagic fever in Delhi, India. Emerg Infect Dis 1999;5:589-90.

10. Gupta E, Dar L, Narang P, Srivastava VK, Broor S. Serodiagnosis of dengue during an outbreak at a tertiary care hospital in Delhi. Indian J Med Res 2005;121:36-8.

11. Garg A, Garg J, Rao YK, Upadhyay GC, Sakhuja S. Prevalence of dengue among clinically suspected febrile episodes at a teaching hospital in North India. J Inf Dis Immunol 2011;3:85-9.

12. Gupta N, Srivastava S, Jain A, Chaturvedi UC. Dengue in India. Indian J Med Res 2012;136:373-90.

13. Normile D. Tropical medicine. Surprising new dengue virus throws a spanner in disease control efforts. Science 2013;342:415.

14. Blacksell SD, Newton PN, Bell D, Kelley J, Mammen MP Jr., Vaughn DW, et al. The comparative accuracy of 8 commercial rapid immunochromatographic assays for the diagnosis of acute dengue virus infection. Clin Infect Dis 2006;42:1127-34.

15. Halstead SB. Dengue. Lancet 2007;370:1644-52.

16. WHO/TDR. Dengue Guidelines for Diagnosis, Treatment, Prevention and Control. Geneva, Switzerland: WHO Press; 2009.

17. Shepard DS, Halasa YA, Tyagi BK, Adhish SV, Nandan D, Karthiga KS, et al. Economic and disease burden of dengue illness in India. Am J Trop Med Hyg 2014;91:1235-42.

18. National Vector Borne Disease Control Programme. Dengue Cases and Deaths in the Country since 2007. Ministry of Health and Family Welfare, Directorate General of Health Services; 2013. Available from: http:/ / www.nvbdcp.gov.in/den-cd.html. [Last accessed on 2018 Jun 20].

19. Moorthy M, Chandy S, Selvaraj K, Abraham AM. Evaluation of a rapid immunochromatographic device for the detection of IgM \& IgG antibodies to dengue viruses (DENV) in a tertiary care hospital in South India. Indian J Med Microbiol 2009;27:254-6.

20. Pun R, Shah Y, Gupta GP, Sherchand SP, Pandey BD. Prognostic value of rapid test for diagnosis of dengue in Nepalese patients during 2010 epidemic. Kathmandu Univ Med J 2012;37:7-10.

21. Mai C, Nam NV, Giao PT, Le Hung LQ, Tran QB. Evaluation of 2 ICT for diagnosis dengue among Vietnamese febrile patients. Clin Vaccine Immunol 2007;14:799-801.

22. Gan VC, Tan LK, Lye DC, Pok KY, Mok SQ, Chua RC, et al. Diagnosing dengue at the point-of-care: Utility of a rapid combined diagnostic kit in Singapore. PLoS One 2014;9:e90037.

23. Tontulawat $\mathrm{P}$, Pongsiri $\mathrm{P}$, Thongmee $\mathrm{C}$, Theamboonlers A, Kamolvarin N, Poovorawan Y, et al. Evaluation of rapid immunochromatographic NS1 test, anti-dengue IgM test, semi-nested PCR and IgM ELISA for detection of dengue virus. Southeast Asian J Trop Med Public Health 2011;42:570-8.

24. Wang S, Sharmala DS. Evaluation of a commercial SD dengue virus NS1 antigen capture enzyme-linked immunosorbent assay kit for early diagnosis of dengue virus infection. J Clin Microbiol 2010;48:2793-7.

25. Sánchez-Vargas LA, Sánchez-Marce EE, Vivanco-Cid H. Evaluation of the SD BIOLINE dengue duo rapid test in the course of acute and convalescent dengue infections in a Mexican endemic region. Diagn Microbiol Infect Dis 2014;78:368-72.

26. Pramiladevi R, Kaivalya D. Study of rapid serological tests for diagnosis of dengue. Sch J App Med Sci 2013;1:548-51.

27. Vaughn DW, Nisalak A, Kalayanarooj S, Solomon T, Dung NM, Cuzzubbo A, et al. Evaluation of a rapid immunochromatographic test for diagnosis of dengue virus infection. J Clin Microbiol 1998;36:234-8.

28. Groen J, Koraka P, Velzing J, Copra C, Osterhaus AD. Evaluation of six immunoassays for detection of dengue virus-specific immunoglobulin $\mathrm{M}$ and $\mathrm{G}$ antibodies. Clin Diagn Lab Immunol 2000;7:867-71.

29. Martínez-Vega RA, Díaz-Quijano FA, Coronel-Ruiz C, Yebrail Gómez S, Villar-Centeno LA. Evaluation of PANBIO rapid immunochromatographic cassette for dengue diagnosis in a Colombian endemic area. Biomedica 2009;29:616-24.

30. Shukla MK, Singh N, Sharma RK, Barde PV. Utility of dengue NS1 antigen rapid diagnostic test for use in difficult to reach areas and its comparison with dengue NS1 ELISA and qRT-PCR. J Med Virol 2017;89:1146-50. 